\title{
EVALUATION OF SOME GROWTH FACTORS AS BIOMARKERS IN PATIENTS WITH PRIMARY AND METASTATIC LIVER CANCER
}

\author{
ALI M. BAKR ${ }^{1}$, MOTAWA E. EL HOUSSEINI ${ }^{2}$, MOHAMED O. REFAIE ${ }^{3}$. \\ MOHAMED A. BASHANDY ${ }^{4}$ \\ ${ }^{1}$ Biochemistry Department, Faculty of Oral \& Dental Medicine, Misr International \\ University. \\ ${ }^{2}$ Biochemistry Unit, Cancer Biology Department, National Cancer Institute, Cairo \\ University. \\ ${ }^{3}$ Laboratory of Biomedical Analysis, Faculty of Science, Cairo University \\ ${ }^{4}$ Zoology Department, Faculty of Science, Al-Azhar University.
}

\begin{abstract}
Additional novel serum markers are still needed in case of malignancies such as hepatocellular carcinoma (HCC), not only for diagnosis but also for prognosis, evaluation and follow-up of the patients. Growth factors thought to be involved in the growth of both primary and metastatic malignancies such as liver cancers include transforming growth factor alpha (TGF- $\alpha$ ), transforming growth factor beta (TGF- $\beta$ ) and vascular endothelial growth factor (VEGF). Therefore, the objective of this study was to evaluate their diagnostic significance as biomarkers of primary and metastatic liver cancer, their serum levels were determined by ELISA in 25 healthy persons, 25 patients with primary liver cancer and 25 patients with metastatic liver cancer. This study revealed that the serum levels of TGF- $\alpha$, TGF- $\beta 1$ and VEGF were significantly high $(\mathrm{p}<0.001)$ in patients with primary liver cancer compared to control group. Moreover, their serum levels were much significantly higher $(p<0.001)$ in patients with metastatic liver cancer compared to the primary liver cancer group. These results suggest that serum levels of TGF- $\alpha$, TGF- $\beta 1$ and VEGF might be valuable biomarkers to predict primary cancers such as liver cancer and for predicting metastasis, as their serum levels are markedly elevated in patients with primary and metastatic malignancy.
\end{abstract}

\section{Introduction}

Hepatocellular carcinoma (HCC) is the most frequent epithelial malignancy of the liver. It rates as the seventh most common malignancy in males and the ninth most in females. Although, great improvements have been made in the diagnosis and therapy of HCC, survival is still poor even for those patients with better clinical and pathological features. This is mainly because of recurrence of the HCC after surgery, or to the presence of disseminated micronodules that rapidly grow and invade the remaining liver parenchyma, affecting prognosis, survival, and life expectation (EI Serag et al., 2001 and El-Zayadi et al., 2001).

Many biological processes including wound healing, development and carcinogenesis involve defined patterns of cellular growth and differentiation. Rates of proliferation and pathways of differentiation are regulated and dependent upon precise and coordinated networks of intercellular communication. Malignant 
transformation might result from excessive production of growth promoting polypeptides by cancer cells themselves, which both secrete and respond to these factors. (Cruz et al., 2007 and Pawlik and Choti, 2007)

\section{Transforming growth factor alpha (TGF- $\alpha$ )}

Transforming growth factor alpha (TGF- $\alpha$ ) is a 50 -amino-acid polypeptide that are derived from a 160-residue precursor by proteolytic cleavage. It is a $6 \mathrm{kDal}$ polypeptide with $40 \%$ sequence homology to the epidermal growth factor (EGF), with which it shares a common receptor. TGF- $\alpha$ is physically constrained into three ring structures by disulfide bridges formed between six cysteine residues. It has been isolated from a retrovirus-transformed mouse cell line, it has subsequently been found in human tumor cells and in normal keratinocytes from human adults (Coffey et al., 1987). The roles for TGF- $\alpha$ have been proposed in transformation, wound healing, bone resorption, angiogenesis, and cell migration (Schultz et al., 1987). TGF- $\alpha$ is a potent positive effector of hepatocyte growth and probably acts in the regenerating liver through an autocrine mechanism (Norstedt et al., 1988).

\section{Transforming growth factor beta (TGF- $\beta$ )}

The transforming growth factor beta (TGF- $\beta$ ) superfamily contains proteins that serve a wide variety of biologic functions, including growth control, cellular differentiation, embryologic morphology, and immunity. Transforming growth factor- $\beta 1$ (TGF- $\beta 1$ ) is the predominant form found in humans and is expressed widely in a variety of normal cells and organs. TGF- $\beta 1$ is a multifunctional polypeptide, promoting angiogenesis, accumulation of extracellular matrix glycoproteins, and cell adhesion proteins, while inhibiting growth of both epithelial and immune cells (Tsushima et al., 1996). Each isoform is a 25 Dal homodimeric peptide composed of two peptide chains, of 112 amino-acids in length and containing a conserved motif of 9 cysteine residues. Of these 9 cysteines, 6 participate in formation of 3 interlocking intramonomeric disulphide bonds which are buried within, and stabilize each monomer. (MacKay et al., 1995 and Markowitz et al., 1996).

\section{Vascular endothelial growth factor (VEGF)}

Vascular endothelial growth factor (VEGF) is one of the most important growth and survival factors for endothelium. VEGF induces angiogenesis and endothelial cell proliferation and it plays an important role in regulating vasculogenesis. VEGF is a heparin-binding glycoprotein that is secreted as a homodimer of $42 \mathrm{kDa}$. Three receptors tyrosine kinases have been described as putative VEGF receptors and have been shown to bind VEGF with high affinity. They are VEGFR-1 (Flt-1) (fms-like 
tyrosine kinase), VEGFR-2 (KDR/Flk-1) (kinase-insert-domain-containing receptor) and VEGFR-3 (Flt-4) (Soker et al., 1998 and Huang et al., 2005). 


\section{Materials and Methods}

The study was carried out on 50 patients admitted to the medical oncology unit of the National Cancer Institute and 25 normal apparently healthy persons as a control, from December 2009 to June 2010. The work was carried out in the Biochemistry Unit, Cancer Biology Department, National Cancer Institute. Patients included and normal persons were categorized into the following:

- $\quad$ Group I: includes 25 normal apparently healthy persons as a control.

- Group II: includes 25 Patients with primary Hepatocellular Carcinoma (HCC).

- Group III: includes 25 Patients with metastatic Hepatocellular Carcinoma (metastatic to lung).

The final diagnosis of the cases was based on histopathological examination of surgical specimens. Tumor staging and grading were determined according to TNM and World Health Organization Classification.

\section{Specimen Collection and Assay Method}

Blood samples were collected preoperatively and preserved on ice tile reaching the lab, blood samples were collected with no additives to obtain serum. Samples were centrifuged for 15 minutes at $3000 \mathrm{rpm}$ and the serum was separated and kept frozen at $\left(-80^{\circ} \mathrm{C}\right)$ until assayed. The Human TGF- $\alpha$, TGF- $\beta 1$ and VEGF ELISA (Enzyme-Linked Immunosorbent Assay) kits are obtained from Ray Bioß. They are in vitro enzyme-linked immunosorbent assay for the quantitative measurement of human TGF- $\alpha$, TGF- $\beta 1$ and VEGF in serum.

\section{Rsults}

The age of the control group ranged from 30 to 57 years, 15 persons (60\%) were males and 10 persons (40\%) were females. While the age of primary liver cancer patients ranged from 43 to 69 years, eighteen patients (72\%) were males and seven patients (28\%) were females. Moreover, the age of metastatic liver cancer patients ranged from 47 to 62 years, 14 patients (56\%) were males and 11 patients (44\%) were females.

Transforming Growth Factor alpha (TGF- $\alpha$ )

Table (1): The statistical analysis of serum levels of the transforming growth factor alpha (TGF- $\alpha$ ) in all groups of the study.

\begin{tabular}{|l|l|l|l|}
\hline \multicolumn{2}{|c|}{ Groups } & \multirow{2}{*}{ Control (G I) pg/ml } & \multicolumn{2}{|c|}{ Tested groups pg/ml } \\
\cline { 3 - 4 } Data & & Primary HCC (G II) & Metastatic HCC (G III) \\
\hline
\end{tabular}




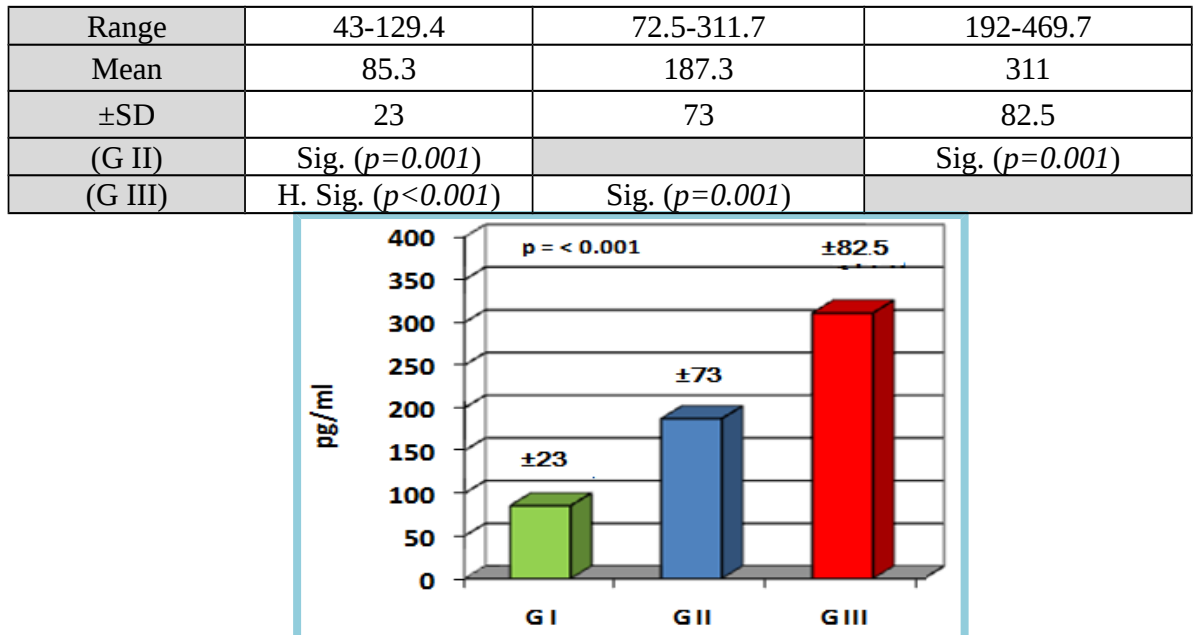

Figure (1): mean serum level of TGF- $\alpha$ in all groups

\section{Receiver Operating Curve (ROC) Analysis:}

The ROC curve analysis of serum levels of TGF- $\alpha$ has been done to calculate the best cut off value. In primary HCC group versus control group, the area under the curve is 0.903 , standard error is 0.049 . The curve shows that the sensitivity of TGF$\alpha$ is $84 \%$ and its specificity is $90 \%$, at a cut-off point of $(140 \mathrm{pg} / \mathrm{ml})$. And in primary HCC group versus metastatic HCC group, the area under the curve is 0.894 , standard error is 0.054 . The curve shows that the sensitivity of TGF- $\alpha$ is $82 \%$ and its specificity is $88 \%$, at a cut-off point of ( $320 \mathrm{pg} / \mathrm{ml})$.

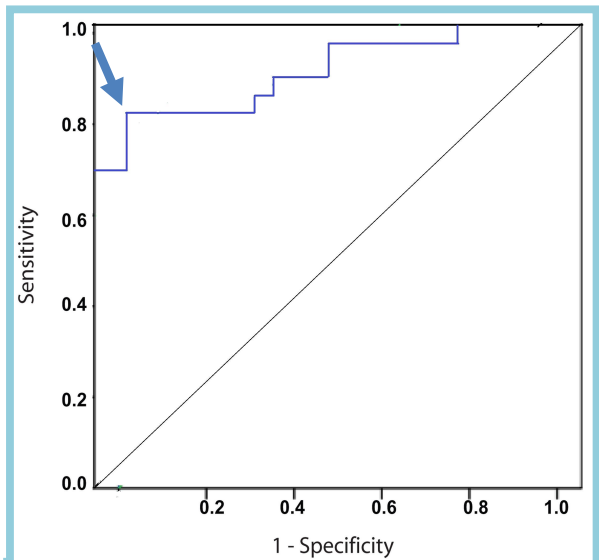

Figure (2): ROC curve analysis for TGFa (Primary carcinoma vs Control).

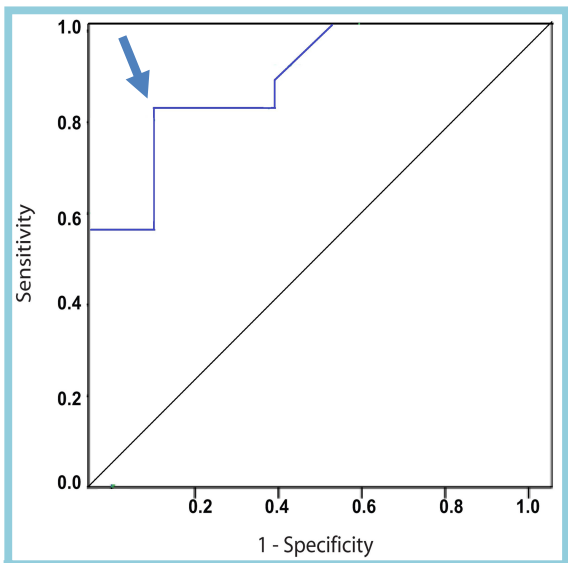

Figure (3): ROC curve analysis for TGF- $\alpha$ (Primary vs. Metastatic)

\section{Scattering diagram}


This diagram illustrates the individual values for serum TGF- $\alpha$ in control group and tested groups, it is obvious that 21 patients with primary HCC have serum TGF$\alpha$ above the cut-off value $(140 \mathrm{pg} / \mathrm{ml})$ while healthy individuals showed no elevations above that cut-off value. And 19 patients with metastatic HCC have serum TGF- $\alpha$ above the cut-off value $(320 \mathrm{pg} / \mathrm{ml})$ while patients with primary HCC showed no elevations above that cut-off value.

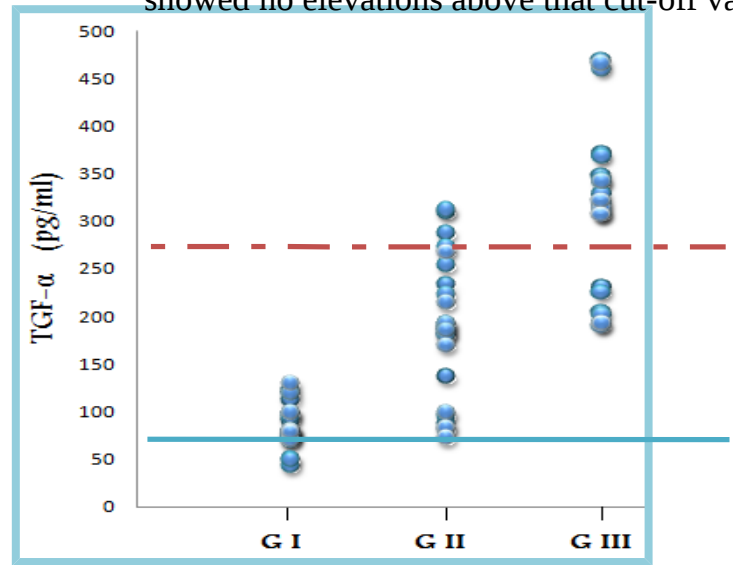

Figure (4): Scattering diagram showing the individual sera levels of TGF- $\alpha$ in all studied groups, the straight line represents the cut-off value between control \& primary cancers dashed line represents the cut-off value between primary \& metastatic HCC.

Transforming growth factor beta 1 [TGF- $\beta 1$ ]:

Table (2): The statistical analysis of serum levels of the transforming growth

\begin{tabular}{|c|c|c|c|} 
factor beta-1 (TGF- $\beta 1$ ) in all groups of the \\
study. \\
\begin{tabular}{|c|c|c|} 
Groups \\
Data
\end{tabular} & $\begin{array}{c}\text { Control } \\
(\mathrm{G} \mathrm{I}) \\
\mathrm{ng} / \mathrm{ml}\end{array}$ & $\begin{array}{c}\text { Tested groups ng/ml } \\
\text { HCC }\end{array}$ & $\begin{array}{c}\text { Metastatic } \\
\text { HCC }\end{array}$ \\
\hline Range & $7.2-24$ & $20.3-33.2$ & $26-49$ \\
\hline Mean & 17 & 26.6 & 40.7 \\
\hline \pm SD & 3.7 & 3.9 & 7 \\
\hline$(\mathrm{G} \mathrm{II})$ & Sig. $(p=0.001)$ & & Sig. $(p=0.001)$ \\
\hline (G III) & H. Sig. $(p<0.001)$ & Sig. $(p=0.001)$ & \\
\hline
\end{tabular}

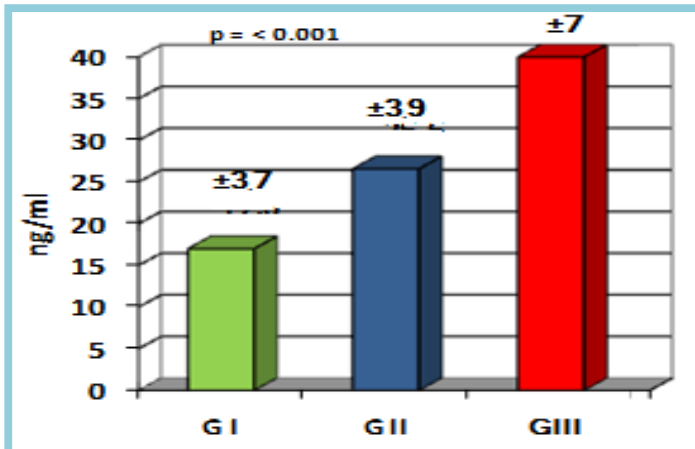

Figure (5): mean serum level of TGF- $\beta 1$ in all 


\section{Receiver Operating Curve (ROC) Analysis}

In primary HCC group versus control group, the area under the curve is 0.889 , standard error is 0.043 . The curve shows that the sensitivity of TGF- $\beta 1$ is $80 \%$ and its specificity is $90 \%$, at a cut-off point of $(24 \mathrm{ng} / \mathrm{ml})$. And in primary HCC group versus metastatic HCC group, the area under the curve is 0.786 , standard error is 0.069 . The curve shows that the sensitivity of TGF- $\beta 1$ is $78 \%$ and its specificity is $84 \%$, at a cut-off point of (34 ng/ml).

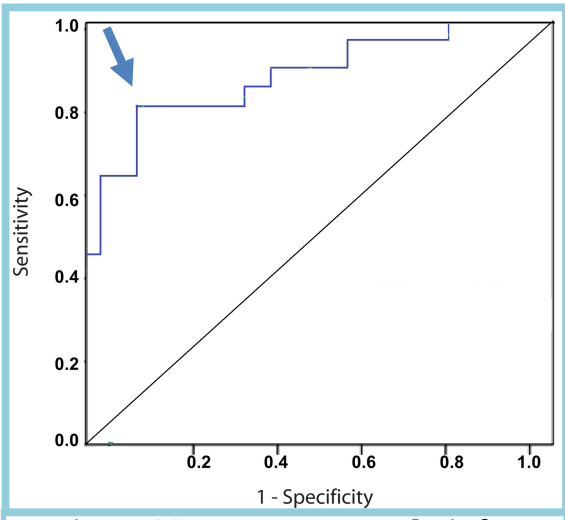

Figure (6): ROC curve analysis for TGFß1 (primary carcinoma vs control).

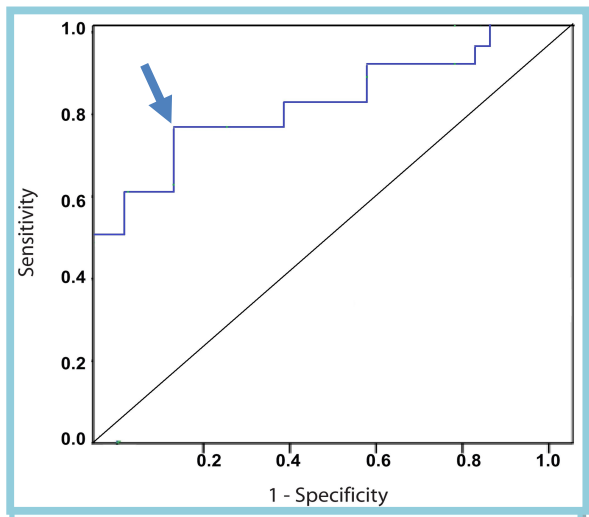

Figure (7): ROC curve analysis for TGF 1 (Primary vs Metastatic).

\section{Scattering diagram}

This diagram illustrates the individual values for serum TGF- $\beta 1$ in control group and tested groups, it is obvious that 21 patients with primary HCC have serum TGF$\beta 1$ above the cut-off value $(24 \mathrm{ng} / \mathrm{ml})$ while healthy individuals showed no elevations above that cut-off value. And 20 patients with metastatic HCC have serum TGF- $\beta 1$ above the cut-off value $(34 \mathrm{ng} / \mathrm{ml}$ ) while patients with primary HCC showed no elevations above that cut-off value.

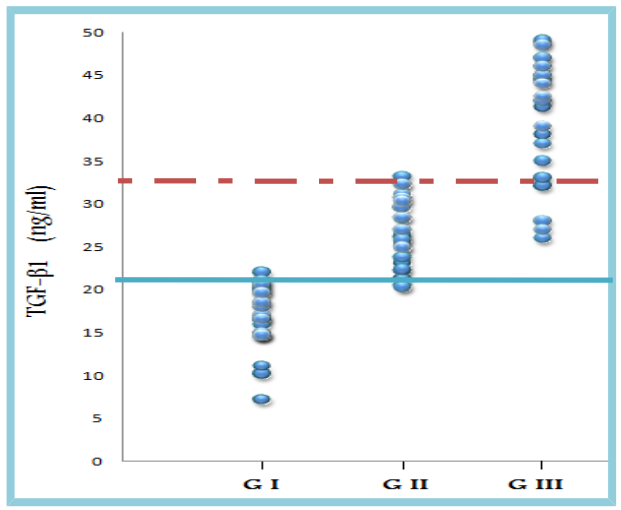


Figure (8): Scattering diagram showing the sera levels of TGF- $\beta 1$ in all studied groups.

The straight line represents the cut-off value between control \& primary cancers.

Dashed line represents the cut-off value between primary \& metastatic HCC.

Vascular endothelial growth factor [VEGF]:

Table (3): The statistical analysis of serum levels of the vascular endothelial growth factor (VEGF) in all groups of the study.

\begin{tabular}{|c|c|c|c|}
\hline \multirow{2}{*}{ Groups } & \multirow{2}{*}{$\begin{array}{c}\text { Control } \\
(\mathrm{G} \mathrm{I}) \\
\mathrm{pg} / \mathrm{ml}\end{array}$} & $\begin{array}{l}\text { Tested groups pg/ml } \\
\text { Patary } \\
\text { HCC }\end{array}$ & $\begin{array}{c}\text { Metasta } \\
\text { tic } \\
\text { HCC } \\
(\mathrm{G} \mathrm{III})\end{array}$ \\
\hline Range & $58-116$ & $178-467$ & $340-873$ \\
\hline Mean & 96.3 & 318.7 & 582.2 \\
\hline \pm SD & 13.4 & 85.9 & 189.2 \\
\hline$(\mathrm{G}$ II) & Sig. $(p=0.001)$ & & Sig. $(p=0.001)$ \\
\hline$(\mathrm{G}$ III $)$ & H. Sig. $(p<0.001)$ & Sig. $(p=0.001)$ & \\
\hline
\end{tabular}

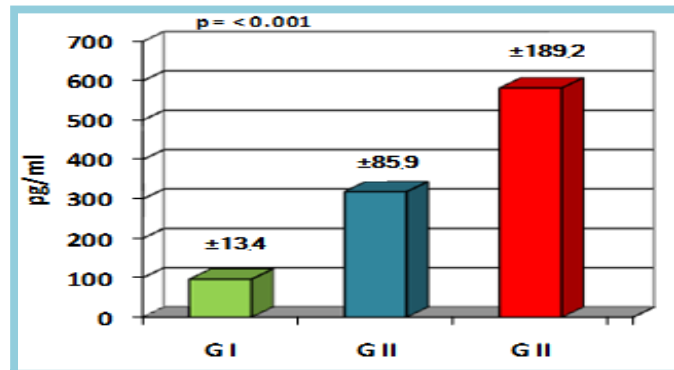

Figure (9): mean serum level of TGF- $\beta$ in all groups

\section{Receiver Operating Curve (ROC) Analysis}

In primary HCC group versus control group, the area under the curve is 0.959 , standard error is 0.001 . The curve shows that the sensitivity of VEGF is $94 \%$ and its specificity is $99 \%$, at a cut-off point of $(140 \mathrm{pg} / \mathrm{ml})$. And in primary HCC group versus metastatic HCC group, the area under the curve is 0.853 , standard error is 0.052 . The curve shows that the sensitivity of VEGF is $84 \%$ and its specificity is $83 \%$, at a cut-off point of $(490 \mathrm{pg} / \mathrm{ml})$.

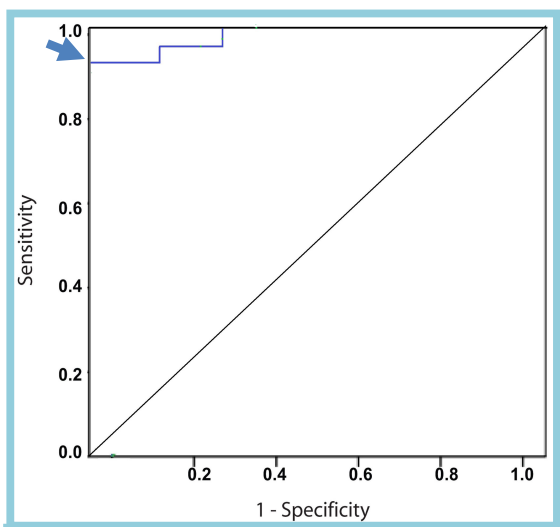

Figure (10): ROC curve analysis for VEGF (primary carcinoma vs control).

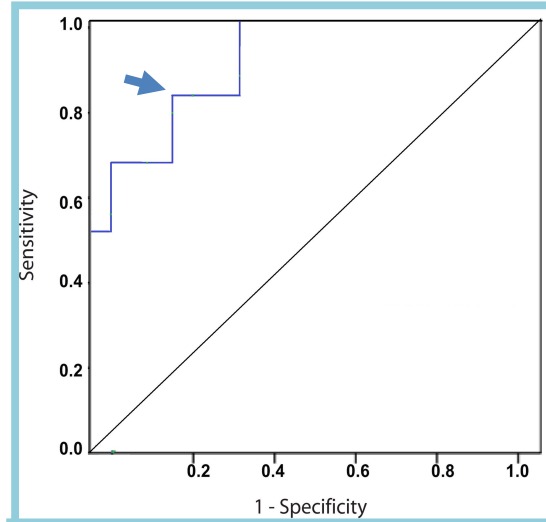

Figure (11): ROC curve analysis for VEGF (primary vs metastatic) 


\section{Scattering diagram}

This diagram illustrates the individual values for serum VEGF in control group and tested groups, it is obvious that 25 patients with primary HCC have serum VEGF above the cut-off value $(14 \mathrm{pg} / \mathrm{ml})$ while healthy individuals showed no elevations above that cut-off value. And 21 patients with metastatic HCC have serum VEGF above the cut-off value $(490 \mathrm{pg} / \mathrm{ml})$ while patients with primary HCC showed no elevations above that cut-off value.

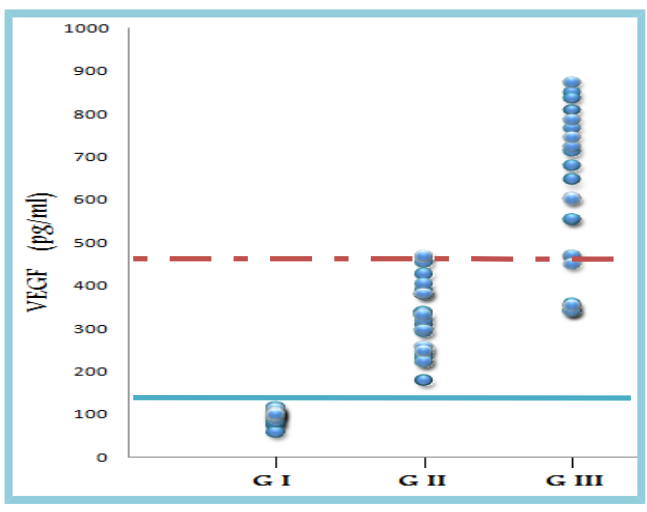

Figure (12): Scattering diagram showing the sera levels of VEGF in all studied groups. The straight line represents the cut-off value between control \& primary cancers. Dashed line represents the cut-off value between primary \& metastatic HCC

\section{Discussion}

Our experimental results revealed that the mean serum level of TGF- $\alpha$ in normal healthy group was found to be $85.3 \mathrm{pg} / \mathrm{ml}$, which is consistent with the normal level obtained from the study done by Tahara (2005), which was $72 \mathrm{pg} / \mathrm{ml}$. Moreover, our results showed that the mean serum level of TGF- $\alpha$ in primary liver cancer was found to be significantly higher than the control group $(p<0.001)$. Furthermore, the comparison of the mean serum level of TGF- $\alpha$ in metastatic liver cancer and primary liver cancer in our work has clearly showed that TGF- $\alpha$ is useful marker for predicting metastatic HCC. The receiver operating curve (ROC) analysis showed high sensitivity and specificity of TGF- $\alpha$ in predicting primary liver cancer and metastatic liver cancer.

Our results agreed with what have demonstrated by (Parkin \& Bray, 2001 and Deric et al., 2010) who have observed over-expression of TGF- $\alpha$ and reported that 
serum level of TGF- $\alpha$ is extremely elevated in liver cancer. They suggested that TGF- $\alpha$ stimulates DNA synthesis in cells especially in hepatocytes. It seems that a key part of the control of liver regeneration rests in the liver itself. This control mechanism may involve autocrine circuits in which hepatocytes respond to TGF- $\alpha$ that they themselves produce or paracrine mechanisms that involve interactions between hepatocytes and other liver cells such as endothelial and Kupffer cells. In vivo, the elevation of TGF- $\alpha$ coincided with maximal rates of hepatocyte DNA synthesis. At the same time, hepatocytes do not undergo DNA synthesis in culture in the absence of TGF- $\alpha$.

This agrees with the findings reported by D'Errico et al (2000) who demonstrated that elevated serum TGF- $\alpha$ and protein overexpression were significantly associated with tumor progression $(p=0.02)$ and metastasis $(p<0.05)$ suggesting that TGF- $\alpha$-positive carcinomas could have a more aggressive biological phenotype. Moreover, our results are supported by Dutta and Maity (2007) who suggested that since TGF- $\alpha$ expression was associated with lymph node metastasis; its detection in serum and biopsies might identify patients with metastatic tumors who may need additional therapy.

In our experimental study we have obtained the serum level of TGF- $\beta 1$ in control group and it was found to be $17 \mathrm{ng} / \mathrm{ml}$, which is consistent with the normal level obtained from the study Kyrtsonis et al (1998) who have reported that the normal range of serum TGF- $\beta 1$ is $(1-33 \mathrm{ng} / \mathrm{ml})$. Regarding to the normal mean serum level of obtained in our study, this work revealed that the mean serum level of TGF- $\beta 1$ in primary liver cancer was found to be significantly higher than the control group ( $p<$ $0.001)$, and its serum level was much significantly higher $(\mathrm{p}<0.001)$ in patients with metastatic liver cancer compared to the primary liver cancer. According to the receiver operating curve (ROC) analysis, TGF- $\beta 1$ showed high sensitivity and specificity in predicting primary liver cancer as well as metastatic liver cancer.

Our results agreed with the findings of several authors (Massague et al., 2000; Sacco et al., 2000; Song et al., 2002; Dong et al., 2007; Wright et al., 2007 and Wrighton et al., 2008) who have reported an elevated level of TGF- $\beta 1$ in serum of patients with hepatocellular carcinoma as compared with those in normal adults and patients with non-malignant hepatopathy, and showed to be closely related to invasion and metastasis. They also found that patients with more advanced tumors have higher serum levels of TGF- $\beta 1$. Therefore, they suggested that serum TGF- $\beta 1$ may reflect the severity of invasive cancer. They attributed this elevation in serum level of TGF- $\beta 1$ to the TGF- $\beta 1$ signaling pathway that plays a critical role in several essential biological processes, including cell proliferation, differentiation, migration, and apoptosis. Moreover, they demonstrated that TGF- $\beta 1$ has been shown to promote angiogenesis as well as regulate cell adhesion, motility, and the extracellular matrix, and these various processes collectively can lead to enhanced tumor invasion and metastasis. 
Several authors (Biswas et al., 2004; Rebecca et al., 2005; Xu and Pasche, 2007; Adorno et al., 2009 and Bierie, 2009) supports our experimental results, they observed an elevation in serum TGF- $\beta 1$ in patients with invasive tumors and metastasis. That elevation was attributed to the process of proteolysis that the tumor cells use to invade the surrounding stroma, where highly malignant and invasive cells show increased protease activity when compared with normal and poorly invasive cells. Suggesting that, TGF- $\beta 1$ modulates proteolytic activity by upregulating plasminogen activator in human prostate cancer, while it stimulates basement membrane lysis by increasing type IV collagenase production in extramedullary tumor sites in metastatic carcinomas.

Regarding VEGF findings, our experimental results revealed that its mean serum level in control group was found to be $96.3 \mathrm{pg} / \mathrm{ml}$, which is consistent with what have been shown by Amo et al (2002) who has reported that the normal range of serum VEGF is (57.8 $-156.7 \mathrm{pg} / \mathrm{ml})$. With respect to the normal mean value obtained in our work, the mean serum level of VEGF in primary liver cancer was found to be significantly higher $(p<0.001)$. Moreover, the comparison of the mean serum level of VEGF in metastatic cancers and primary cancers in this work clearly showed the ability of VEGF to predict metastatic liver cancer, where the mean serum level of VEGF in metastatic HCC group was significantly higher than primary HCC group $(p<0.001)$. The receiver operating curve (ROC) analysis shows high sensitivity and high specificity of VEGF in predicting both primary and metastatic liver cancer.

Our results agreed with the findings of (Kim et al., 2004 and Takahashi et al., 2003) who noted that serum VEGF is significantly higher in HCC patients than in normal adults and patients with nonmalignant hepatopathy. He suggested that high serum VEGF is associated with advanced stage of HCC and shorter overall survival. Therefore, it may be a useful diagnostic or prognostic indicator for HCC.

(Bates et al., 2003; Reinmuth et al., 2003; Hirakawa et al., 2007; Tonra \& Hicklin, 2007; Fernandez et al., 2008 and Karpanen \& Alitalo 2008) joined that serum VEGF is significantly higher in HCC patients than in normal adults and it is the most potent angiogenic molecule. They have also shown a correlation between neovascularization in tumors and VEGF expression. They have reported that there is a strong relationship between the serum level of VEGF and the metastatic potential of liver cancers.

\section{Conclusion}

Our findings in this work suggest that serum TGF- $\alpha$, TGF- $\beta$ and VEGF could be useful as tumor markers to predict primary hepatocellular carcinoma (HCC) and for predicting metastasis, as their serum levels are markedly elevated in patients with primary and metastatic malignancy, in comparison with normal healthy individuals. Moreover, they may be considered as a target for therapy as they are directly associated with the malignant transformation, invasion, migration and metastasis. And the multiple tumor-permissive effects of these growth factors provide a 
therapeutic opportunity, in which blocking this signaling network interrupts several autocrine and paracrine mechanisms that are essential for tumor maintenance.

\section{References:}

1. Adorno, M. Cordenonsi, M. Montagner, M. Wong, C. Solari, A. (2009). A mutantp53/Smad complex opposes p63 to empower TGF ${ }^{3}$-induced metastasis. Cell, 137: 8798.

2. Amo Y, Masuzawa M, Hamada Y, Katsuoka K. (2002). Serum concentrations of vascular endothelial growth factor in angiosarcomas with and without p53 gene mutation. Acta dermato-venereologica, 82(5):373-4.

3. Bates RC, Goldsmith JD, Bachelder RE. (2003). Flt-1-dependent survival characterizes the epithelial-mesenchymal transition of colonic organoids. Curr. Biol, 13 (19): 1721-7.

4. Bierie B, Chung CH, Parker JS, Stover DG, Cheng N, Chytil A, Aakre M, Shyr Y, Moses HL (2009): Abrogation of TGF-beta signaling enhances chemokine production and correlates with prognosis in human breast cancer. J. Clin. Invest, 119:1571-1582.

5. Biswas S, Chytil A, Washington K. (2004) Transforming growth factor beta receptor type II inactivation promotes the establishment and progression of colon cancer. Cancer Res, 64:4687-4692.

6. Coffey, R. J., R. Derynck, J. N. Wilcox, T. S. Bringman, A. S.Goustin, H. L. Moses, and M. R. Pittelkow. (1987) Production and auto-induction of transforming growth factor- $\alpha$ in human keratinocytes. Nature, 328:817-820.

7. Cruz J, Ocana A, Del Barco E, Pandiella A. (2007) Targeting receptor tyrosine kinases and their signal transduction routes in head and neck cancer. Ann. Oncol, 18 (3): 421-30.

8. D'Errico A, Barozzi C, Fiorentino M, Carella R, Di Simone M, Ferruzzi L, Mattioli S, Grigioni WF.(2000). Role and new perspectives of transforming growth factor-alpha (TGF-alpha) in adenocarcinoma of the gastro-oesophageal junction. Br. J. Cancer, 82(4):865-70.

9. Deric L. Wheeler, Emily F. Dunn \& Paul M. Harari. (2010). TGF-alpha signaling pathway. Nature Reviews Clinical Oncology. 7: 493-507.

10. Dong ZZ, Yao DF, Zou L, Yao M, Qiu LW, Wu XH, Wu W. (2007) An evaluation of transforming growth factor-beta in diagnosing hepatocellular carcinoma and metastasis. 15: 503-508.

11. Dutta, P. R. and Maity, A. (2007). Cellular responses to EGFR inhibitors and their relevance to cancer therapy. Cancer Lett. 254: 165-177.

12. El Serag HB. (2002) Hepatocellular carcinoma: an epidemiologic view. J. Clin. Gastroenterol, 35 (Suppl 2): S72-78.

13. El-Zayadi A, Abaza H, Shawky S, Mohamed MK, Selim OE, Badran HM. (2001) Prevalence and epidemiological features of hepatocellular carcinoma in Egypt-a single center experience. Hepatol Res, 19: 170-179.

14. Fernandez MI, Bolenz C, Trojan L, Steidler A, Weiss C, Alken P, Grobholz R, Michel MS (2008): Prognostic implications of lymphangiogenesis in muscle-invasive transitional cell carcinoma of the bladder. Eur Urol, 53:571-578. 
15. Hirakawa S, Brown LF, Kodama S, Paavonen K, Alitalo K, Detmar M (2007): VEGF induced lymphangiogenesis in sentinel lymph nodes promotes tumor metastasis to distant sites. Blood, 109:1010-1017.

16. Huang GW, Yang LY, Lu WQ (2005) Expression of hypoxia-inducible factor 1alpha and vascular endothelial growth factor in hepatocellular carcinoma: impact on neovascularization and survival.World J Gastroenterol, 11:1705-8.

17. Karpanen T, Alitalo K (2008): Molecular biology and pathology of lymphangiogenesis. Annu Rev Pathol, 3:367-397.

18. Kim SJ, Choi IK, Park KH. (2004) Serum vascular endothelial growth factor per platelet count in hepatocellular carcinoma: correlations with clinical parameters and survival. Jpn J Clin Oncol 34:184-90.

19. Kyrtsonis MC, Repa C, Dedoussis GV, Mouzaki A, Simeonidis A, Stamatelou M, Maniatis A. (1998). Serum transforming growth factor-beta1 is related to the degree of immunoparesis in patients with multiple myeloma. Med oncol. 15(2):124-8.

20. MacKay SL, Yaswen LR, Tarnuzzer RW, Moldawer LL, Bland KI, Copeland EM,. (1995) Colon cancer cells that are not growth inhibited by TGF-beta lack functional type I and type II TGF-beta receptors. Ann Surg 221:767-76.

21. Markowitz SD, Roberts AB. (1996) Tumor suppressor activity of the TGF-beta pathway in human cancers. Cytokine Growth Factor Rev 7:93-102.

22. Massague J, Blain SW, Lo RS. (2000) TGFbeta signaling in growth control, cancer, and heritable disorders. Cell, 103:295-309.

23. Norstedt, G., Levinovitz, A., Moller, C., Eriksson, L. C., Andersson, G. (1988) Carcinogenesis 9, 209-213.

24. Parkin DM., Bray, F. (2001) Estimating the world cancer burden Globocan 2000. Int. J. Cancer 94; 153- 156.

25. Pawlik TM, Choti MA. (2007) Shifting from clinical to biologic indicators of prognosis after resection of hepatic colorectal metastases. Curr. Oncol. Rep, 9 (3): 193-201.

26. Rebecca S. Muraoka-Cook, Dumont N, and Arteaga C. ( 2005). Dual Role of Transforming Growth Factor B in Mammary Tumorigenesis and Metastatic Progression. Clinical Cancer Research, 11: 937s-943s.

27. Reinmuth N, Parikh AA, Ahmad SA. (2003). Biology of angiogenesis in tumors of the gastrointestinal tract. Microsc. Res. Tech, 60 (2): 199-207.

28. Sacco R, Leuci D, Tortorella C.(2000) Transforming growth factor beta1 and soluble Fas serum levels in hepatocellular carcinoma. Cytokine, 12:811-4.

29. Schultz, G. S., M. White, R. Mitchell, G. Brown, J. Lynch, D. R. Twardzik, and G. J. Todaro. (1987) Epithelial wound healing enhanced by transforming growth factor- $\alpha$ and vaccinia growth factor. Science, 235:350-352.

30. Soker S, Takashima S, Miao HQ, Neufeld G \& Klagsbrun M (1998) Neuropilin-1 is expressed by endothelial and tumor cells as an isoform specific receptor for vascular endothelial growth factor. Cell, 92: 735-745.

31. Song BC, Chung YH, Kim JA. (2002) Transforming growth factorbeta1 as a useful serologic marker of small hepatocellular carcinoma. Cancer, 94:175-80. 
32. Tahara E (2005). Growth factors and oncogenes in gastrointestinal cancers. In: Meyers RA (ed) Encyclopedia of molecular cell biology and molecular medicine, 6. 2nd edn. pp $1-31$.

33. Takahashi Y, Ellis LM, Mai M. (2003) Oncol. Rep, 10:9-13.

34. Tonra JR, Hicklin DJ. (2007). Targeting the vascular endothelial growth factor pathway in the treatment of human malignancy. Immunol. Invest, 36 (1): 3-23.

35. Tsushima H, Kawata S, Tamura S, Ito N, Shirai Y, Kiso S,. (1996) High levels of transforming growth factor beta 1 in patients with colorectal cancer: association with disease progression. Gastroenterology, 110:375-82.

36. Wright, L.M., Kreikemeier, J.T. and Fimmel, C.J. (2007) A concise review of serum markers for hepatocellular cancer. Cancer Detect Prev , 31, 35-44.

37. Wrighton, Katharine H; Lin Xia, Feng Xin-Hua. (2008). Critical regulation of TGFbeta signaling by Hsp90. Proc. Natl. Acad. Sci. U.S.A. (United States) 105 (27): 9244-9.

38. Xu Y, Pasche B. (2007) TGF-beta signaling alterations and susceptibility to colorectal cancer. Hum. Mol. Genet, 16:R14-20. 